\title{
Iron decarburisation techniques in the eastern Guanzhong Plain, China, during Late Warring States period: an investigation based on slag inclusion analyses
}

https://doi.org/10.1007/s12520-019-00921-5

\author{
Authors \\ Yaxiong Liu', Marcos Martinón-Torres ${ }^{2}$, Jianli Chen ${ }^{3}$, Weigang Sun ${ }^{4}$, Kunlong Chen ${ }^{1,5}$ \\ 1 UCL Institute of Archaeology, 31-34 Gordon Square, London WC1H OPY, UK \\ 2 Department of Archaeology, University of Cambridge, Cambridge CB2 3ER, UK \\ ${ }^{3}$ School of Archaeology and Museology, Peking University, Beijing 100080, China \\ ${ }^{4}$ Shaanxi Provincial Institute of Archaeology, Xi'an 710043, China \\ 5 Institute of Historical Metallurgy and Materials, University of Science and Technology Beijing, Beijing \\ 100083, China
}

\begin{abstract}
Iron production in the Central Plains area of China has been largely based on cast iron smelting since ca. fifth century $\mathrm{BC}$, with different techniques developed in the following Warring States period and Han dynasty to convert this material into malleable soft iron. Whilst there is a broad consensus about the evolution of technological traditions in the Early Iron Age, the methodologies employed for differentiating artefacts derived from different iron smelting and decarburisation methods have been variable and not sufficiently conclusive. Taking advantage of renewed analytical approaches and archaeological evidence recovered in recent years, this paper summarises our current understanding of the decarburisation techniques employed in Early Iron Age China and sheds new light on this subject through the analysis of archaeological artefacts from two civilian cemeteries in the eastern part of the Guanzhong Plain (Shaanxi), dated to the third century BC. The analytical results indicate that both solid-state and liquid-state decarburisation were employed for soft iron production in this area during the Late Warring States period. The methodology employed in this paper, based on slag inclusion analysis, also provides a more systematic approach to differentiating soft iron production techniques in future archaeometallurgical research in China.
\end{abstract}

\section{Keywords}

Archaeometallurgy, Decarburisation, Chaogang, Slag inclusions, Warring States period 


\section{Introduction}

The production of iron in early human history followed two broad technological trajectories: the direct process, also known as bloomery iron smelting, and the indirect process, which involved the production of cast iron followed by decarburisation. These two technical procedures led to widely different technical processes to obtain malleable soft iron.

In the direct process, iron ore is reduced in the solid state at temperatures around $1200^{\circ} \mathrm{C}$, in the form of metallic iron particles that coalesce through the liquid slag to form a low carbon iron bloom with some slag trapped inside. Several steps of hammering and annealing are required to consolidate the iron bloom and expel the slag, and eventually, the product can be further shaped into objects (Killick and Gordon 1988; Pleiner 2000). This technique remained the only method used to smelt iron in Europe, West Asia, and Africa until the Middle Ages (Rostoker and Bronson 1990; Craddock 1995; King 2005).

However, in the Central Plains area of China, large quantities of iron objects made of cast iron start to appear since the fifth century BC, indicating that cast iron smelting was developed and widely adopted by that time (Hua et al. 1960; Li 1975; Yang 1982; Han 1998; Hua 1999; Han and Ko 2007: 384; Wagner 2008: 115; Chen 2014: 231). Cast iron is an iron carbon alloy with carbon levels greater than 2.11 wt. $\%$.

The smelting of such an alloy was carried out in a blast furnace, which operates at a temperature around $1400{ }^{\circ} \mathrm{C}$ and possibly more reducing atmospheres (higher $\mathrm{CO} / \mathrm{CO}_{2}$ ratio) than a bloomery furnace. As a result, the iron ore will be reduced and still have the time and suitable environment to be alloyed with carbon during the smelting process. The melting point of such an iron-carbon alloy can drop to $1146{ }^{\circ} \mathrm{C}$ with a carbon content around $4.3 \mathrm{wt} \%$ (compared to pure iron melting at $1538^{\circ} \mathrm{C}$ ); hence, the separation of metal and slag will be in the liquid state. As the slag and metal can be tapped out separately at the bottom of the furnace, the furnace can be recharged, and the production can continue without stopping for a long period until the furnace needs to be repaired.

The metallic product of the blast furnace smelting is normally white cast iron. Whilst this is suitable for mould-casting due to its low melting point, this alloy is not useful for producing bladed tools or weapons as the cementite in its crystal structure renders this material too hard and brittle, hence unable to undergo any deformation work such as hammering or forging. In these cases, additional processing to convert the raw cast iron into a malleable soft iron will be necessary.

According to current research, an annealing process designed to malleabilise cast iron was adopted during the fifth century $\mathrm{BC}$. In this process, the cast iron was placed into an annealing 
furnace where it was heated up to around $900^{\circ} \mathrm{C}$ (Fig. 1) (Li 1975; Zhao et al. 1985). Under this condition, cementite will decompose into iron and carbon. When the annealing condition is oxidising, carbon will be oxidised into $\mathrm{CO}_{2}$, creating a gradient in carbon concentration whereby carbon atoms inside the metal will migrate to the surface and continue to be burnt away. As a result, this process allowed ancient metalsmiths to bring down the carbon content in cast iron to a desired level. With proper control of time, temperature and atmosphere, this technique provided the first technical solution to convert cast iron into low carbon soft iron, which could be further hammered or forged into final products (Li 1975; Yang 1980; Wagner 1989; Hua 1982).

In addition, previous studies also suggest that another decarburisation technique, known as Chaogang in Chinese literature (“炒钢” in Chinese characters, directly translated as "Stir-fry steel", or "fining" under the modern terminology), may have been employed for soft iron production since the early Han dynasty, around the second century BC (Chen and Han et al. 1999). As described by Han and Ko (2007: 612), the Chaogang process started by re-melting the cast iron in an open hearth with a strong blast creating oxidising conditions to remove the carbon; when the cast iron started to melt, a stirring process was applied to promote oxidation; at the end of the process, a red hot iron bloom-like material was retrieved from the hearth and further hammered to expel the slag and shaped into final products. Despite the uncertainties about the technique details owing to the lack of archaeological evidence, the main feature of such a technique, and the fundamental difference with the annealing process, was that the Chaogang decarburisation is an exothermic reaction with a liquid-gas reaction interface. Depending on the amount of cast iron to be decarburised, this process can take from minutes to a few hours (Yang 1960; Wagner 1985: 60,1989, 2008: 30); hence, it is less time-consuming and theoretically saves fuel compared to the solid-gas annealing process.

Meanwhile, the scarcity of artefacts conclusively identified as made of bloomery iron found in the Central Plains of China and dated to the Early Iron Age (Nanjing Museum 1974; Beijing University of Iron and Steel Technology 1975; Shandong Museum 1977; Han 1989; Bai 1994; Han 1998; Han et al. 1999; Chen et al. 2009), together with the absence of bloomery production sites reported from this period, appears to indicate that such a technique was not widely adopted during the early stages of iron metallurgy. However, the possibility of smallscale bloomery iron production still cannot be ruled out, as it has been pointed out that in some socioeconomic contexts, bloomery iron production can be a more cost-effective method to obtain soft iron; hence, small-scale production could have co-existed with cast iron smelting for a long period (Larreina-Garcia et al. 2018). Having said that, bloomery smelting was widely practiced in the periphery areas of the Central Plains during the Early Iron Age, such as the 
northern Shaanxi, Gansu and Xinjiang (Beijing University of Iron and Steel Technology 1975; Bai 2004; Chen et al. 2012; Huang 2013; Guo et al. 2014); hence, it is also possible that bloomery iron was brought into the Central Plains through trade or migration during that time.

Given the variety of technological pathways to produce soft iron (Fig. 2), mapping their use in time, space and functional contexts is an interesting research avenue to explore the evolution and adaptation of technologies. For this, however, it is essential to develop a methodology that may allow us to discriminate these techniques through the analysis of archaeological materials.

According to the literature, soft iron made through an annealing process (pathway 2.1 in Fig. 2 ) is relatively straight forward to discriminate, as this material has recognisable features such as a clean metal matrix with very few slag inclusions (non-metallic phases trapped in the metal matrix), the gradient in carbon content decreasing from the centre to the surface, or occasional remnants of temper carbon or graphite nodules (Hua et al. 1960; Li 1975; Han 1998). A more challenging issue lies in the differentiation between bloomery iron (pathway 1) and fined iron (pathway 2.2 in Fig. 2) as these two processes can lead to materials with quite similar microstructures, namely little to no carbon content, and relatively abundant slag inclusions with broadly similar chemical compositions.

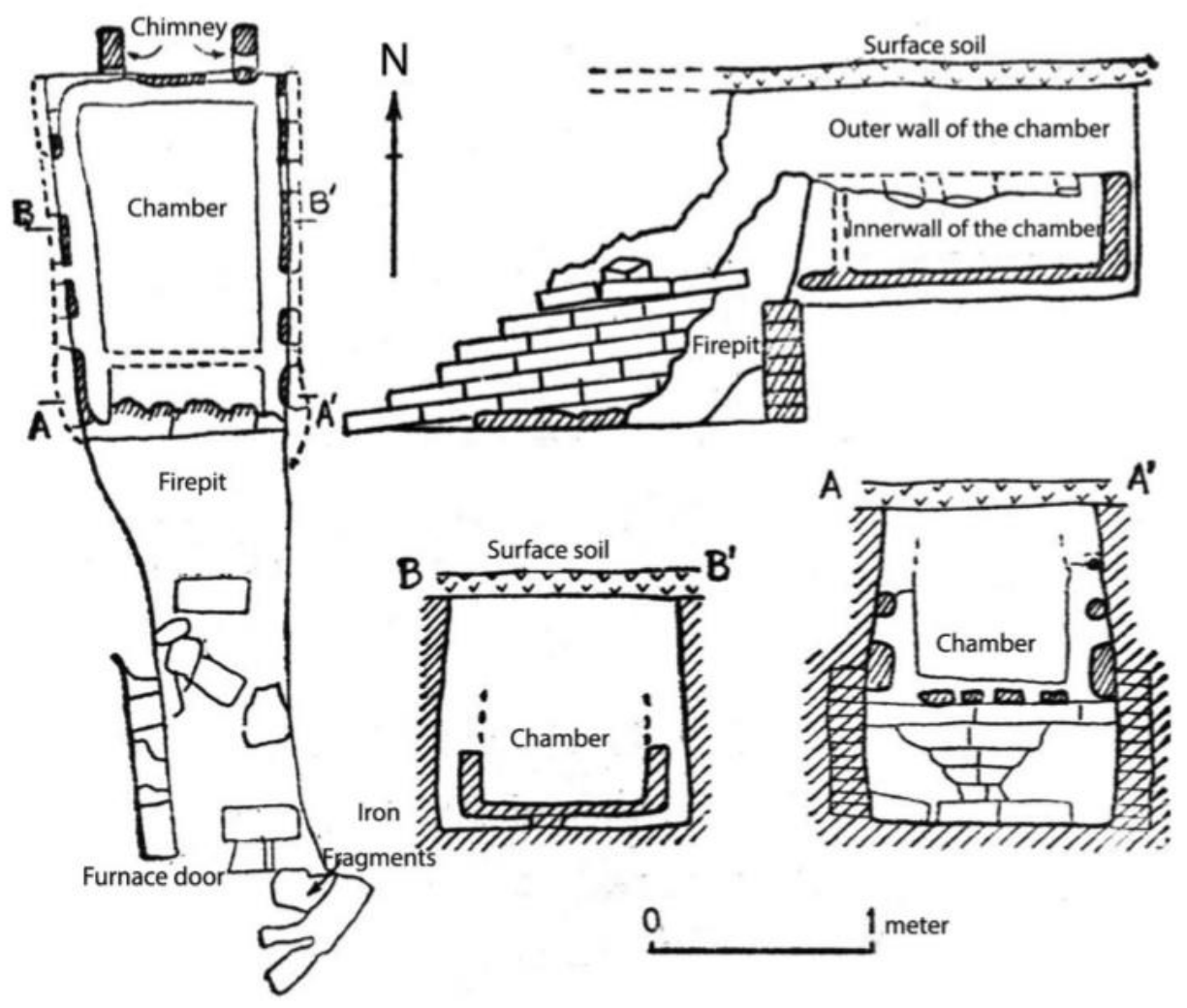

Fig. 1 Diagram of an annealing kiln located in Tieshe'nggou site, Henan province, dated to Han dynasty (Zhao et al. 1985) 
Early approaches to this question in China were largely based on metallography study with limited chemical analyses, whilst at the same time acknowledging the need to establish a repeatable methodology based on quantifiable data (Hua et al. 1960; Beijing University of Iron and Steel Technology 1975; 1976; Ye 1975; Li 1975; 1982; Ko et al. 1993; Han 1998; Chen and Han et al. 1999; Li et al. 2019). More recently, systematic approaches to differentiate these materials based on metallography and slag inclusion analysis were developed (Table 1) (Chen and Han 1999, 2007). This method has subsequently been used by other researchers in China to discriminate archaeological materials. In recent years, scholars have made further progresses in establishing clear discriminating criteria, and concluding that high phosphorus concentration and the presence of $\mathrm{Ca}-\mathrm{P}$ compounds in the slag or slag inclusions may be a marker of the Chaogang (fining) process (Yang et al. 2014; Chen and Zhang 2016; Huang et al. 2016).

In the meantime, archaeometallurgical research in Europe has also focused on the differentiation between direct and indirect products based on slag inclusion analysis, with methods that increasingly involve numerous chemical analyses of slag inclusions followed by statistical analyses of the resulting datasets (Gordon 1997; Buchwald and Wivel 1998; Dillmann and L'Héritier 2007; Biggs et al. 2013; Disser et al. 2014). In particular, Dillmann and L'Héritier (2007) have shown that slag inclusions in iron produced by the indirect method tend to be richer in $\mathrm{P}_{2} \mathrm{O}_{5}$ and have lower levels of other metal oxides such as $\mathrm{MgO}, \mathrm{K}_{2} \mathrm{O}$ and $\mathrm{Al}_{2} \mathrm{O}_{3}$ compared to iron made from the direct process. Despite the different historical and technological contexts, some of these methods may also be useful for comparable research in China.

In this paper, we build on the latest research progress in both materials and analytical methods through the analysis of a collection of iron objects recovered from Xi'an, Shaanxi province, located in the eastern Guanzhong Plain, and dated to third century BC. This is a crucial period during which cast iron production quickly developed and expanded, as a precedent to the highly complex technological system of blast furnaces in the following Han dynasty (Han and Ko 2007; 502, Wagner 2008; 171). Hence, identifying the methods employed to produce soft iron is significant to understand the early evolution of these techniques. As such, our research not only provides a methodological reference for future research, but also sheds new light on the current understanding of the development of iron production techniques in early Iron Age China. 


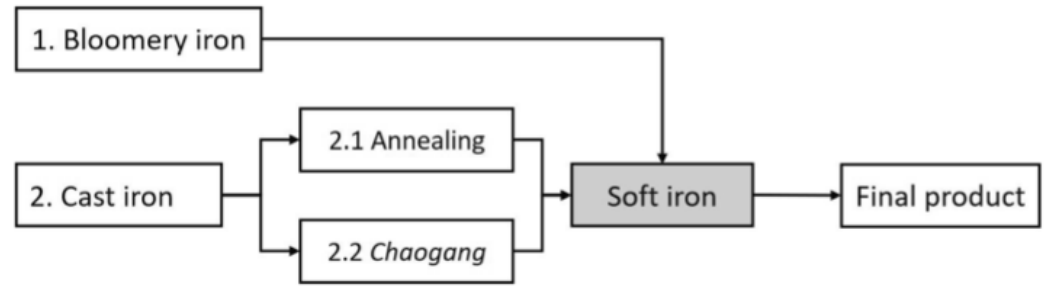

Fig. 2 Technological pathways to soft iron production through direct and indirect processes

\begin{tabular}{|c|c|c|}
\hline & Metallography & Slag inclusions \\
\hline Bloomery iron & Ferrite grains & $\begin{array}{l}\text { Iron oxide inclusions, mostly wüstite-fayalite } \\
\text { eutectic (type I), minor deformation in one } \\
\text { preferential orientation }\end{array}$ \\
\hline Carburised bloomery steel & $\begin{array}{l}\text { Unevenly distributed ferrite and pearlite, } \\
\text { with layered microstructure, and occasionally } \\
\text { findings of a carburisation layer }\end{array}$ & $\begin{array}{l}\text { Iron oxide inclusions, mostly wüstite-fayalite } \\
\text { eutectic (type I), minor deformation in one } \\
\text { preferential orientation }\end{array}$ \\
\hline Solid-decarburised cast iron & $\begin{array}{l}\text { Clean and homogeneous microstructure, with } \\
\text { little to no graphite, and occasional cast } \\
\text { iron remnants }\end{array}$ & $\begin{array}{l}\text { Very few inclusions, mainly glassy silicate } \\
\text { inclusions (type II), minor deformation }\end{array}$ \\
\hline Fined iron & $\begin{array}{l}\text { Homogeneous or layered microstructure } \\
\text { with consistent carbon content } \\
\text { between different layers }\end{array}$ & $\begin{array}{l}\text { Mainly glassy silicate inclusions with smaller } \\
\text { size and large deformation, and occasional } \\
\text { findings of slag inclusions with intermediate } \\
\text { microstructure between Type I and Type II }\end{array}$ \\
\hline
\end{tabular}

Table 1 Approaches for the identification of different materials according to Chen and Han (Chen and Han 2007: p. 32)

\section{Materials and analytical methods}

The samples selected for this research are mainly edged tools or weapons, which based on their typology and external appearance, were suspected to be made of soft iron through forging process (Fig. 3, Table 2). These samples came from two adjacent cemeteries located in the suburbs of Xi'an City, Shaanxi province (Fig. 4): the Xinfeng and Xiekou cemeteries, belonging to the State of Qin and dated to the late stage of the Warring States period (around third century BC). Based on the pottery typology and relevant inscriptions, these are believed to be the public cemeteries for local civilians who may have been involved in the construction of the Mausoleum of the first Qin Emperor (Sun 2009). The iron artefacts were found in the tomb chambers along with other burial goods such as pottery, bronze and jade. These cemeteries have also yielded large numbers of other types of iron objects, such as cooking pots, tripods and farming implements such as shovels and adzes. A total number of 28 of them were sampled and identified as made of cast iron through mould-casting after initial metallographic examination (see supplementary material s1). 
In addition, legacy samples from past research conducted in 1999 (Chen and Han 1999), believed to constitute the earliest evidence of Chaogang (fining) technique in China, were also analysed. In the original research, sample 2432, a knife, was proposed to be made of Chaogang iron combined with bloomery iron (pathways 2.2. and 1, respectively). Sample 2440 , a chisel, was identified as made of soft iron through the solid-state decarburisation of cast iron (pathway 2.1). These samples were excavated from a royal tomb of the Han dynasty, located in Xuzhou, Jiangsu province. In order to re-examine the results as well as the methodology, these two samples were re-polished and analysed along with the other 7 samples from Xi'an following the same analytical protocol.

Except for the two legacy samples which were already embedded in bakelite blocks, all samples from Xi'an were mounted in epoxy resin blocks and polished to a $1 \mu \mathrm{m}$ surface with diamond paste, then etched with $3 \%$ nital. Metallography was carried out using a Leica DM 4500 microscope. After the metallographic study, samples were polished again to remove the etched layer, then carbon-coated for SEM-EDS analysis. The analysis was carried out at the UCL Institute of Archaeology, using a Philips XL30 ESEM with an Oxford Instruments EDS detector equipped with INCA software. The accelerating voltage was $20 \mathrm{kV}$, with a working distance of $10 \mathrm{~mm}$ and a live time of $100 \mathrm{~s}$. Cobalt calibration was performed every hour to control for drift. Precision and accuracy were monitored through the measurement of basalt standards. All results are presented as stoichiometric oxides and normalised to $100 \%$ (see supplementary material $\mathrm{s} 2$ ).

During the analysis, as many slag inclusions as possible from each sample were analysed to obtain an unbiased and statistically representative dataset. To analyse the whole area in single-phase glassy slag inclusions, we used the auto-selecting tool in the INCA programme, which is based on the brightness difference between slag inclusion and the iron matrix. For slag inclusions with multiple phases such as wüstite and fayalite crystals, the area was selected by manually drawing a polygon covering as much area as possible. It is worth mentioning that the auto selection of areas will inevitably include a small portion of the surrounding metal matrix, resulting in a slightly higher iron concentration (up to 5 wt.\%), and correspondingly a dilution of other elements after normalisation. 


\section{Analytical results}

\section{Metallography}

The metallographic study of iron samples can reveal plenty of technical information. For instance, the approximate carbon content can be evaluated based on the proportion of different phases (ferrite, pearlite, cementite, etc.). This is particularly important given the impossibility to reliably quantify the carbon content by SEM-EDS on carbon-coated samples. Manufacturing techniques such as smithing, welding, carburisation and quenching can also be inferred from the microstructure as such processes leave diagnostic microstructures; hence, metallography is usually the very first step to initiate the analysis of iron samples.

In our case, the metallographic study shows that most of the samples have relatively low carbon contents, between wrought/bloomery iron and hypo-eutectoid steel $(C<0.77 \%)$, rendering both the hardness and toughness suitable for bladed tools or weapons. Among these samples, F19 (Fig. 5a), F29 and Kn11 display a homogeneous microstructure with uniform carbon content; graphite nodules can be observed in the matrix of sample $\mathrm{Kn} 11$. Sample F26 shows a microstructure with higher carbon content in the core and lower carbon content in the surface (Fig. 5b). Samples Saw1 (Fig. 5c) and 2440 display a gradual increase in carbon content from one side to the other, suggesting a possible carburisation process during manufacturing process. Sample F17 has martensite structures, indicating the metal was quenched during the manufacturing process (Fig. 5d). Samples Kn10 and 2432 have layered microstructures with different carbon contents and grain sizes, indicating a manufacturing process with repeated folding and hammering involved (Fig. 5e, f).

A general description of the microstructure and the estimated carbon content of the samples analysed in this paper is given in Table 3.

\section{SEM-EDS slag inclusion analysis and data treatment: direct or indirect?}

The slag inclusions trapped within metallic iron can derive from different sources during the smelting and manufacturing process. When the slag was not separated from the metal properly during smelting, a certain amount of them will remain within the metal, in the form of inclusions. These are likely to be more abundant in bloomery iron because in this system, there is never a liquid-liquid separation between metal and slag, but the size and abundance of the slag inclusions will vary depending on the skills of smelters and smiths. 


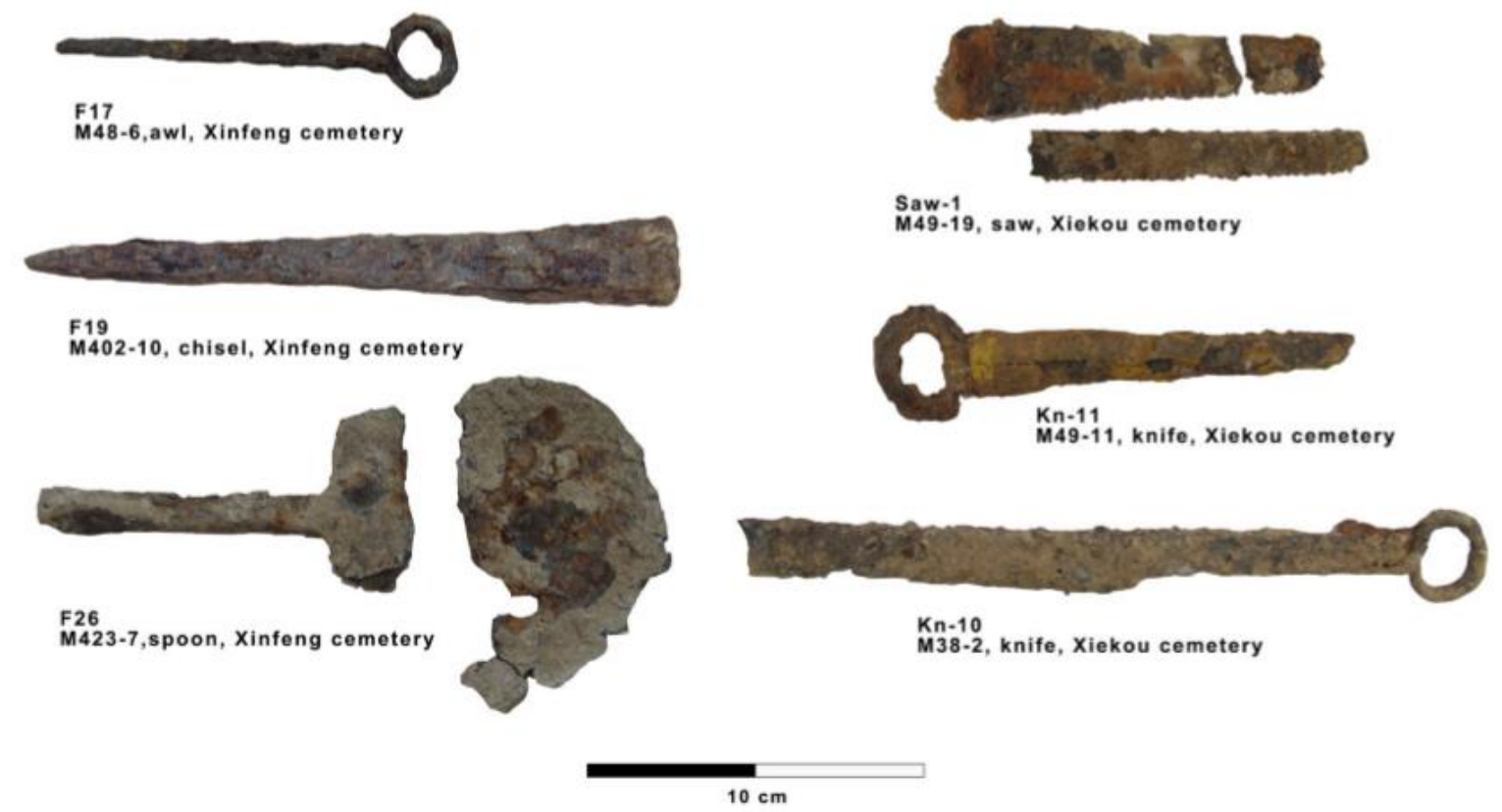

Fig. 3 Photos of iron objects selected for analysis

\begin{tabular}{lllll}
\hline Lab no. & Typology & Excavation no. & Location & Date \\
\hline F17 & Awl & M48-6 & Xinfeng & Late Warring States period \\
F19 & Chisel & M402-10 & Xinfeng & Late Warring States period \\
F26 & Spoon & M423-7 & Xinfeng & Late Warring States period \\
F29 & Sword & M256-16 & Xinfeng & Late Warring States period \\
Saw1 & Saw & M49-19 & Xiekou & Late Warring States period \\
Kn10 & Knife & M49-11 & Xiekou & Late Warring States period \\
Kn11 & Knife & M38-2 & Xiekou & Late Warring States period \\
2432 & Knife & - & Xuzhou & Early Han Dynasty \\
2440 & Chisel & - & Xuzhou & Early Han Dynasty \\
\hline
\end{tabular}

Table 2 Detailed information of samples analysed in this paper

When the metal was further subjected to a fining or smithing process, new slag inclusions may also be formed through metal oxidation, fluxing and reaction with other reagents, whilst the original ones derived from smelting may be physically or chemically altered (Dillmann and L'Héritier 2007; Blakelock et al. 2009; Charlton et al. 2012). Through the analysis of the chemical composition of slag inclusions, combined with the understanding of different techniques and the chemical behaviour of different elements, it is possible to make inferences about their different technical origins. 
For instance, the smelting slag from the direct and indirect processes has some fundamental differences, which should be reflected in the slag inclusions derived from smelting. The direct process normally creates a fayalitic slag $\left(\mathrm{Fe}_{2} \mathrm{SiO}_{4}\right)$ with high iron content (Rehren et al. 2007; Charlton et al. 2010). Conversely, during the cast iron smelting process, which is carried out in more reducing conditions, more iron will be reduced into the metal; hence, the smelting slag will have a much lower iron content, especially when a calcium-rich flux such as limestone was used (Chen and Zhang 2016; Lam et al. 2018). Meanwhile, the use of such a flux will also create a distinctive high calcium concentration that is rarely seen in slag from the direct process.

On the other hand, as noted above, the phosphorus concentration in slag inclusions is also an indicator for different technical processes. Both the ore and the charcoal may contain some phosphorus oxide. In cast iron smelting, most $\mathrm{P}_{2} \mathrm{O}_{5}$ is reduced into the metal, forming $\mathrm{Fe}-\mathrm{P}$ eutectic $\left(\mathrm{Fe}_{3} \mathrm{P}\right)$, with little to no phosphorus left in the slag. In contrast, in the bloomery process, phosphorus oxide is only partly reduced depending on the atmosphere, and it can hardly be absorbed by the solid iron bloom; hence, the $\mathrm{P}_{2} \mathrm{O}_{5}$ content in bloomery slag is generally higher than in blast furnace slag (Dillmann and L'Héritier 2007).

When cast iron is subjected to a decarburisation process, the phosphorus levels may also change accordingly. If the decarburisation was carried out in a liquid state (fining process, pathway 2.2.), the phosphorus in the metal will be re-oxidised and, theoretically, form a stable compound such as $\mathrm{Ca}_{3}\left(\mathrm{PO}_{4}\right)_{2}$ with the calcium oxides in the system (Chen 1990; Dillmann and L'Héritier 2007; Chen and Zhang 2016; Lam et al. 2018). This process will lead to a decrease in the $\mathrm{P}$ concentration in the metallic matrix and significantly high $\mathrm{P}_{2} \mathrm{O}_{5}$ levels in slag inclusions, higher than those normally expected from the direct process. Alternatively, if the decarburisation was carried out in solid state (annealing process, pathway 2.1), phosphorus will not be removed from the metal as the diffusion rate of $P$ in iron is too low under the annealing conditions (Goldstein et al. 2017) and impossible to be removed as $\mathrm{P}_{2} \mathrm{O}_{5}$ gas. As a result, the phosphorus oxide concentration in slag inclusions will remain more or less the same. Thus, the different behaviour of $P$ in annealing and fining processes can give us a chance to discriminate their products based on the $\mathrm{P}$ content in slag inclusions. Based on the above, we derive that the $\mathrm{CaO}$ and $\mathrm{P}_{2} \mathrm{O}_{5}$ levels in the slag inclusions can be used together with metallographic information as the main markers to differentiate iron objects made from direct and indirect processes, as well as whether the metal in the latter was decarburised by either annealing (solid) or fining (liquid) processes. 


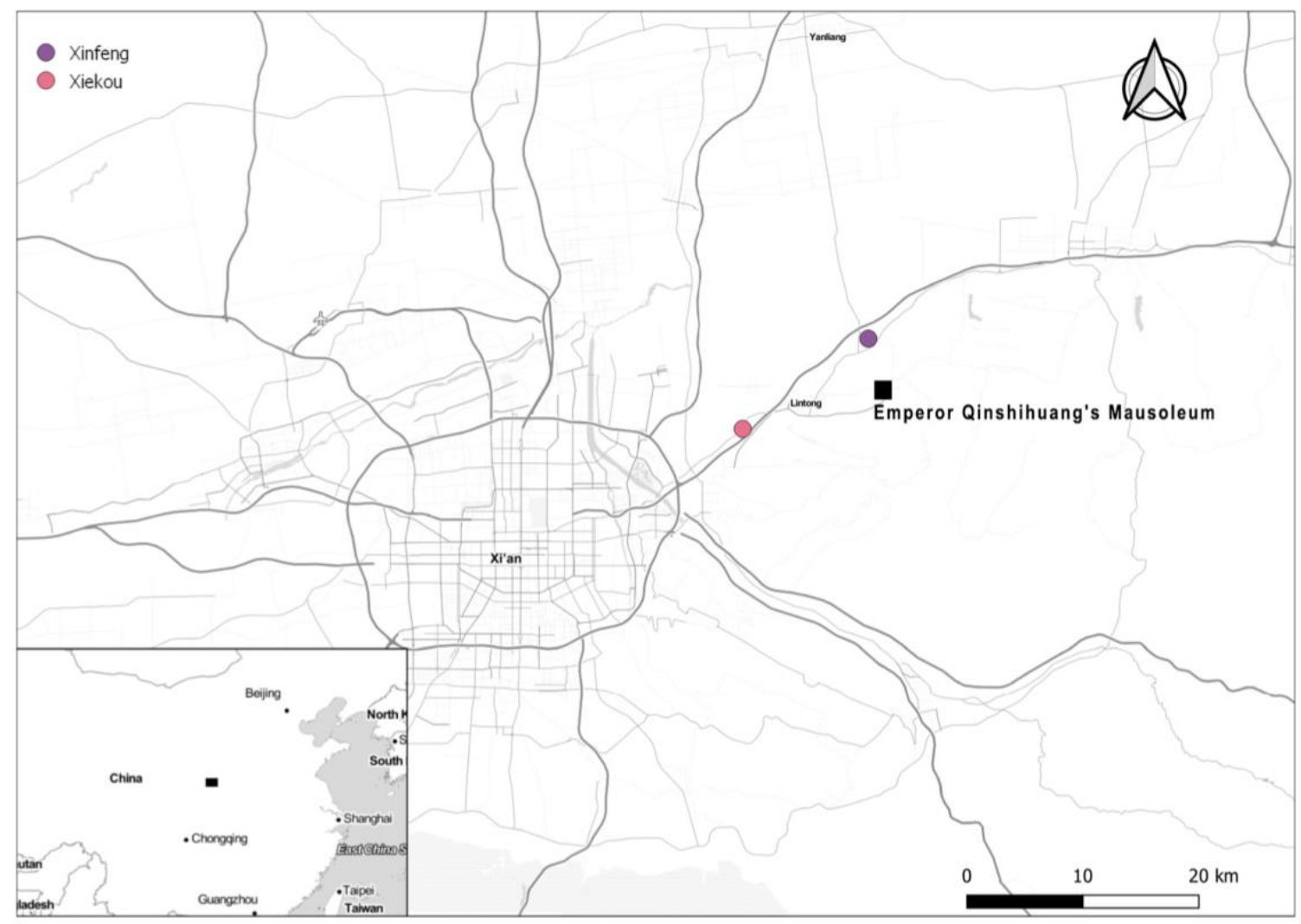

Fig. 4 Location of the Xinfeng and Xiekou cemeteries

\begin{tabular}{|c|c|c|c|c|}
\hline Lab no. & Typology & Description of matrix & C wt.\% & SI analysed \\
\hline F17 & Awl & $\begin{array}{l}\text { From one side to the other, ferrite grains to } \\
\text { Martensite with a layer of Widmannstätten } \\
\text { structure in the middle }\end{array}$ & $0.1 \%$ & 61 \\
\hline F19 & Chisel & Evenly distributed ferrite and pearlite & $0.5 \%$ & 65 \\
\hline F26 & Spoon & Ferrite grains and pearlite & $0.2 \%$ & 33 \\
\hline F29 & Sword & Widmannstätten structure & $0.5 \%$ & 49 \\
\hline Saw1 & Saw & $\begin{array}{l}\text { Ferrite and pearlite, with gradual increase of } \\
\text { carbon content from one side to the other }\end{array}$ & $0.2 \%$ & \\
\hline $\mathrm{Kn} 10$ & Knife & Layered microstructure of ferrite and pearlite & $0.6 \%$ & 24 \\
\hline Kn11 & Knife & Homogenous distribution of fine ferrite and pearlite & $0.4 \%$ & \\
\hline 2432 & Knife & Layered microstructure of ferrite and pearlite & $0.6 \%$ & 42 \\
\hline 2440 & Chisel & $\begin{array}{l}\text { Widmannstätten structure with gradual increase } \\
\text { of carbon content from one side to the other }\end{array}$ & $0.4 \%$ & 26 \\
\hline
\end{tabular}

Table 3 Brief description of the metallography of samples and approximate carbon content 


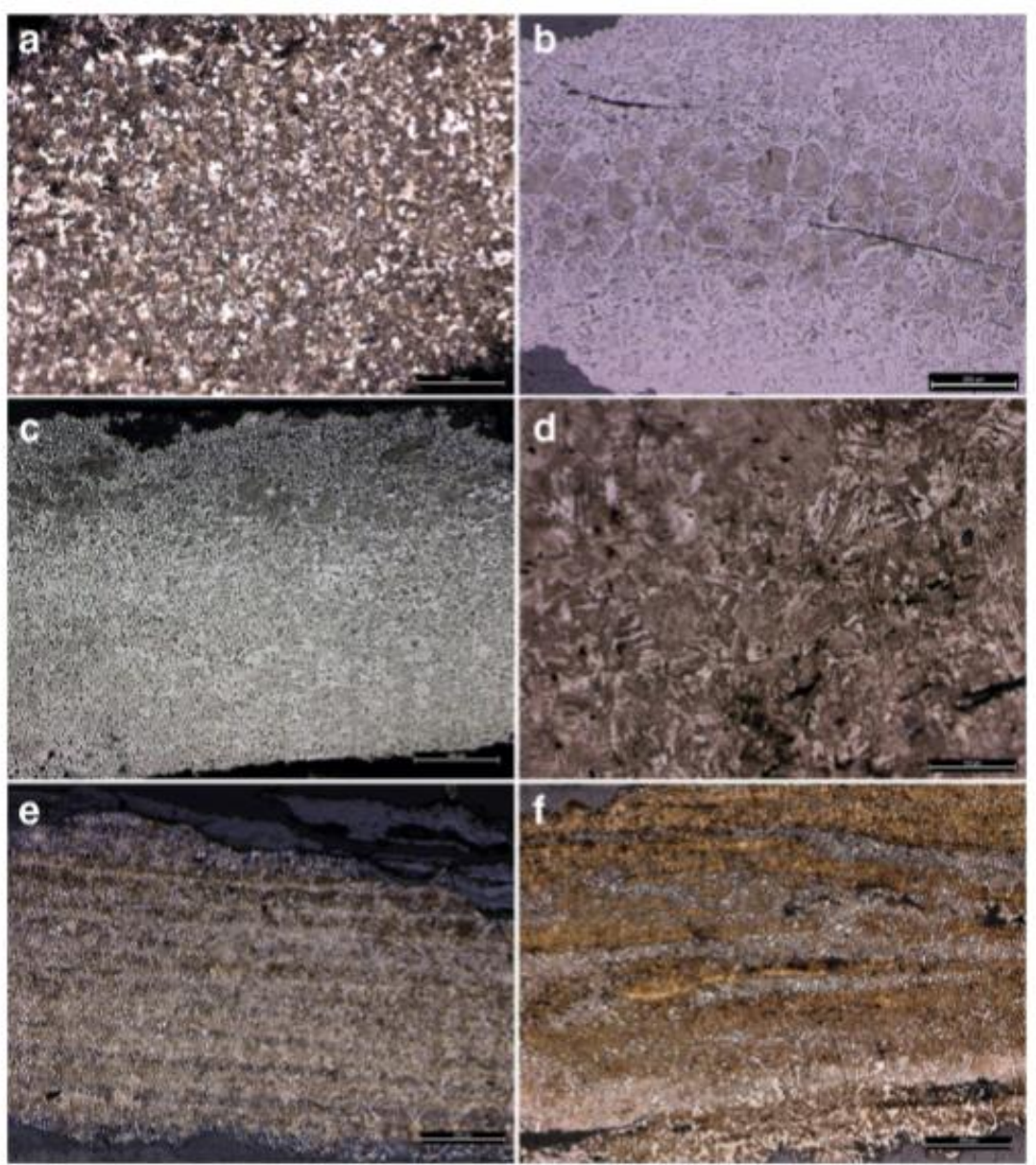

Fig. 5 Metallographic structures of samples Kn10 (a), F26 (b), Saw1 (c), F17 (d), Kn10 (e) and 2432 (f)

It is worth pointing out that there are certain limitations for these criteria to be applied to different sample sets. On one hand, in some cases, it is possible for bloomery systems to produce slag with high $\mathrm{CaO}$ levels, if lime-rich gangue, fluxes or fuel are used (lles and Martinón-Torres 2009), yet the use of calcium-rich ores has rarely been seen in our current research. On the other hand, if neither the iron ore nor the fuel used for smelting contains phosphorus, this element will not be present in the metal or the slag inclusions, which will render the $\mathrm{P}_{2} \mathrm{O}_{5}$ content less effective as an indicator for the production techniques. However, analyses of early cast iron from China show most of them have phosphorus levels between 0.1 and 0.6 wt.\% (Hua 1982; Li 1982; Zhao et al. 1985; Miao et al. 1993), and thus, the aforementioned criteria are arguably to be appropriate for this research.

For the samples analysed in this paper, it is observed that slag inclusions in samples F29, Kn10 and 2440 are homogeneous both chemically and morphologically, featuring glassy slag inclusions with high $\mathrm{SiO}_{2}$ and $\mathrm{CaO}$, and relatively low $\mathrm{FeO}$ content (Fig. 6a, b). Samples F17, F19, F26 and 2432 show high variability in chemical compositions, and the morphology of the 
slag inclusions also varies from glassy silicate to iron oxides (Fig. 6c, d). It is therefore necessary to analyse the data to confirm if there are different slag inclusion families that could be related to different sources or production stages. In this paper, examination of non-reduced compounds (NRC) as proposed by Dillmann and L'Héritier (2007) was applied using $\mathrm{MgO} / \mathrm{Al}_{2} \mathrm{O}_{3}, \mathrm{Al}_{2} \mathrm{O}_{3} / \mathrm{SiO}_{2}$ and $\mathrm{K}_{2} \mathrm{O} / \mathrm{CaO}$ weight percentage ratios (Fig. 7). These compounds, either brought in by charcoal $(\mathrm{MgO}, \mathrm{K} 2 \mathrm{O})$, furnace lining $\left(\mathrm{Al}_{2} \mathrm{O}_{3}, \mathrm{SiO}_{2}\right)$ or the use of fluxing agents $(\mathrm{CaO})$, are not supposed to be reduced in the production process; hence, they should maintain a constant ratio if the slag inclusions were formed in the same production system. However, unlike the above authors, we did not remove abnormal data during the screening process as these data might also be indicative of reactions taking place in inhomogeneous conditions. Instead, every slag inclusion analysed was plotted to qualitatively evaluate their relationships.

Slag inclusions in samples F17 and 2432 appeared to plot in two subclusters in the bivariate plots of NRC concentrations; however, this is largely because the iron oxide concentration varies dramatically among the slag inclusions. After removing other oxides and renormalising the NRC components, the data points collapsed into one group (Fig. 8), indicating these slag inclusions possibly derive from the same source. The same reasoning may be applied to sample F19, with a wider spread but in general within one large group. Sample F26 shows no NRC correlation and subgroups can be seen in the plots of both unnormalized and normalised data, indicating these slag inclusions analysed may derive from different production stages. The plot of $\mathrm{K}_{2} \mathrm{O} / \mathrm{CaO}$ often shows a wider dispersion than those of $\mathrm{MgO} / \mathrm{Al}_{2} \mathrm{O}_{3}$ and $\mathrm{Al}_{2} \mathrm{O}_{3} / \mathrm{SiO}_{2}$, and in samples F26 and 2432 forming two clusters; the underlying mechanism needs to be further explored, but in general, they all show positive correlations.

Of particular significance, most of the slag inclusions analysed contain significant amounts of $\mathrm{CaO}$, which is rarely observed in bloomery smelting products. This indicates that $\mathrm{Ca}$-rich flux was used during the making of such products, in which case, the possibility of direct process can be ruled out. Some of the samples also contain a high amount of $\mathrm{P}_{2} \mathrm{O}_{5}$, suggesting a phosphorus enrichment process, which will be discussed further in the next section (Fig. 9). 

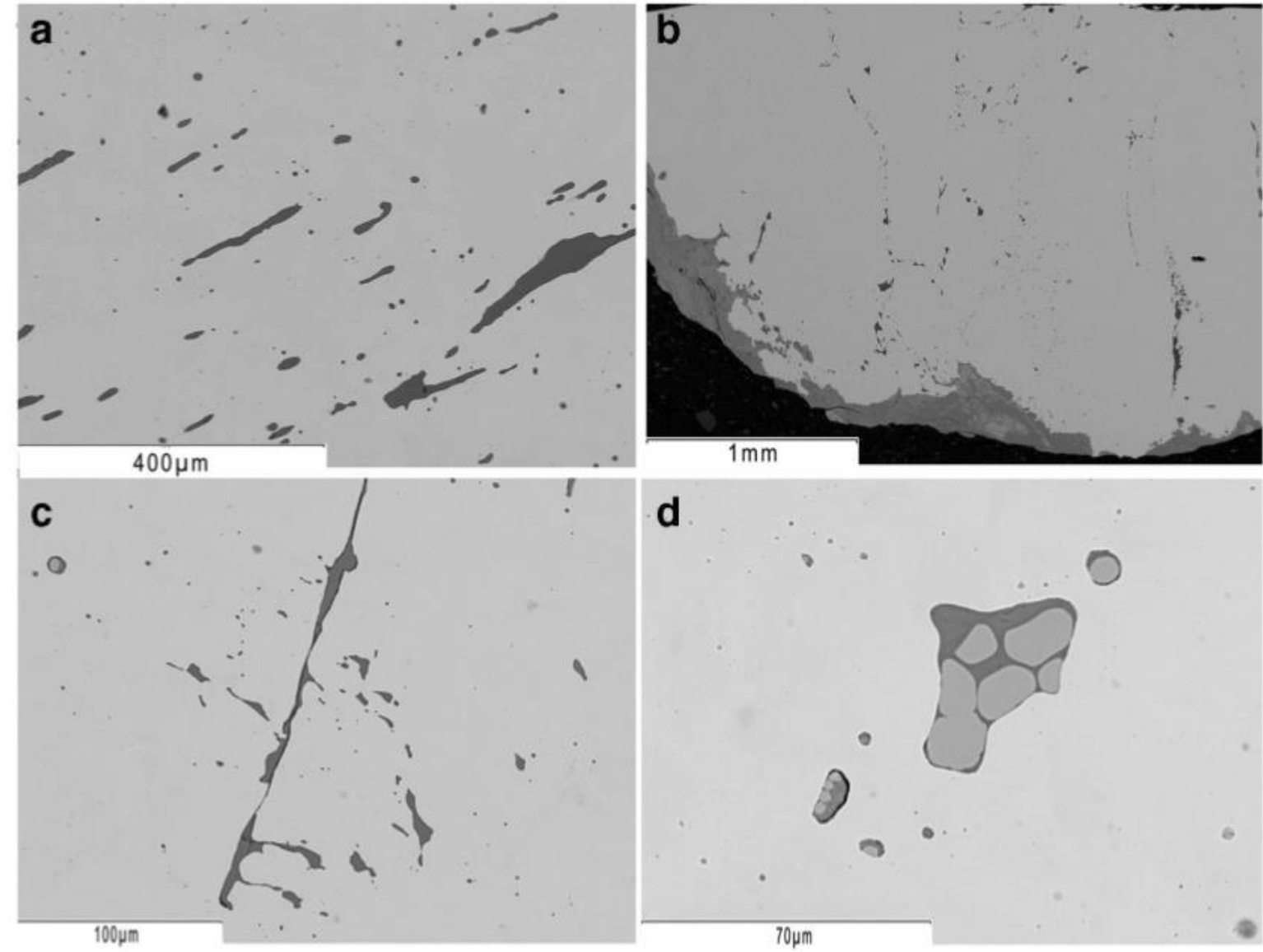

Fig. 6 Backscattered electron images of slag inclusions from F19 (a), 2440 (b) and F17 (c, d)

\section{Discussion: decarburisation methods}

Based on the slag inclusion analysis, the samples in this paper can be distinguished from bloomery iron samples and therefore confirmed to have been derived from the indirect process. Combining this information with the metallography study, more specifics about the raw materials, decarburisation techniques and manufacturing methods can be deduced.

Samples Saw1 and Kn11 show a clean iron matrix with no slag inclusions found under the optical microscope or the SEM (Fig. 10). Given that slag inclusions are to be expected in both bloomery iron and fined iron due to the nature of these techniques, we believe these two samples were made of cast iron decarburised in the solid state. Both samples were further subjected to a forging process which reduced the grain size on the edge, yet no slag inclusions were spotted, suggesting that smithing process does not necessarily introduce new slag inclusions, especially when the microstructure is homogeneous with no signs of folding or welding. 
The rest of the samples contain slag inclusions which should have been introduced primarily after the smelting process, given that the raw material, cast iron, has gone through a thorough slag separation process, and hence, very few smelting slags should remain in the metal. New slag inclusions could either be formed during the Chaogang (fining) process, when the decarburisation of cast iron took place, or during the smithing process (secondary smithing, welding, repairing) where the metal was repeatedly heated and hammered with the use of a flux (most commonly siliceous sand) to prevent oxidisation (McDonnell 1991; Pleiner 2006; 112; Serneels and Perret 2003; Disser et al. 2014; Lam et al. 2018). Such smithing slag could be trapped in the metal when folding or welding was carried out but should be able to be distinguished based on its physical appearance and chemical component. In theory, smithing slag inclusions should be mostly fayalitic, with high $\mathrm{SiO}_{2}$ and $\mathrm{FeO}$ content to reach an optimum melting point (Rehren et al. 2007), and possibly highly deformed, and mostly located in the interface between different zones.

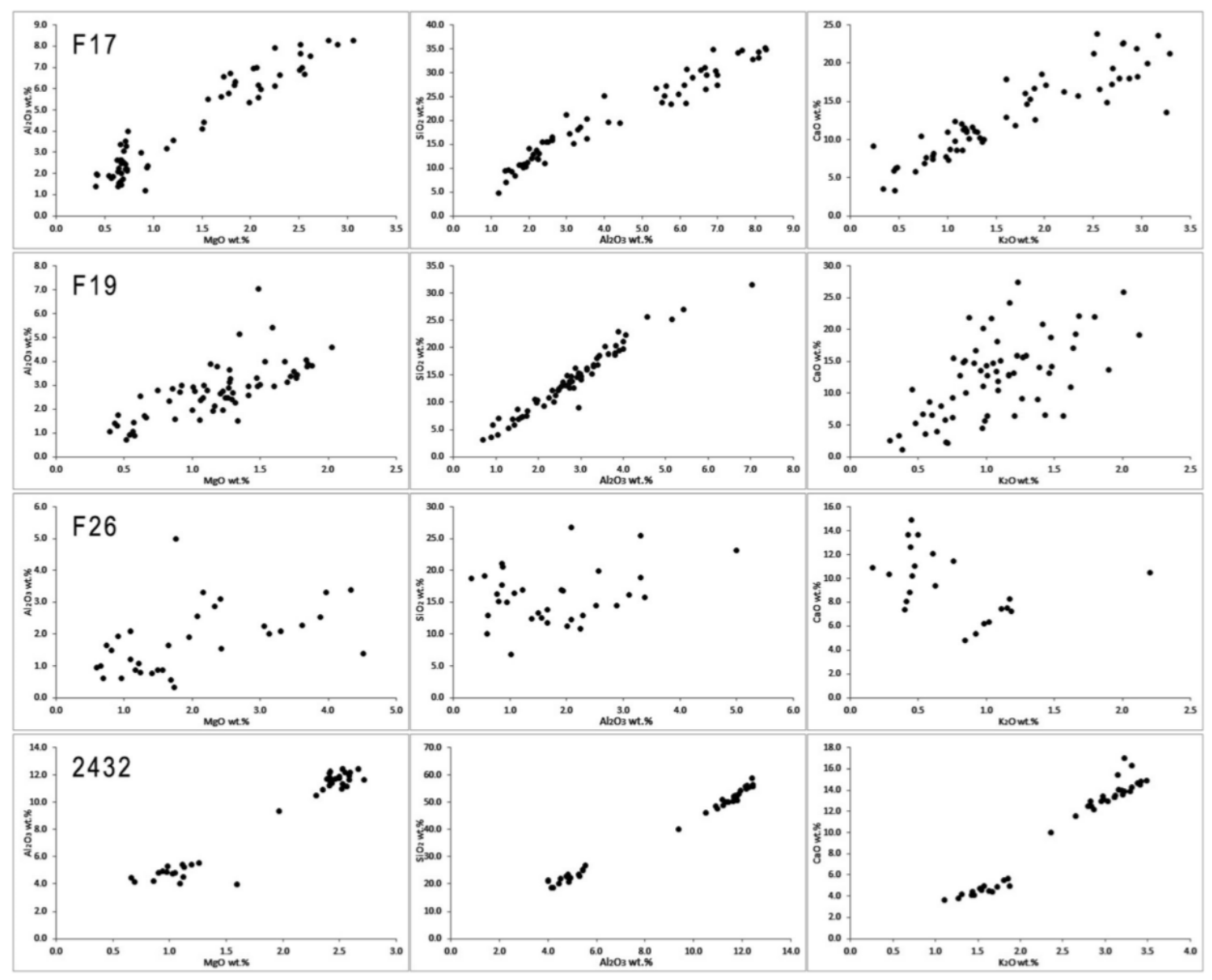

Fig. 7 Bivariate plots of non-reduced compounds (NRC) for samples F17, F19, F26 and 2432 


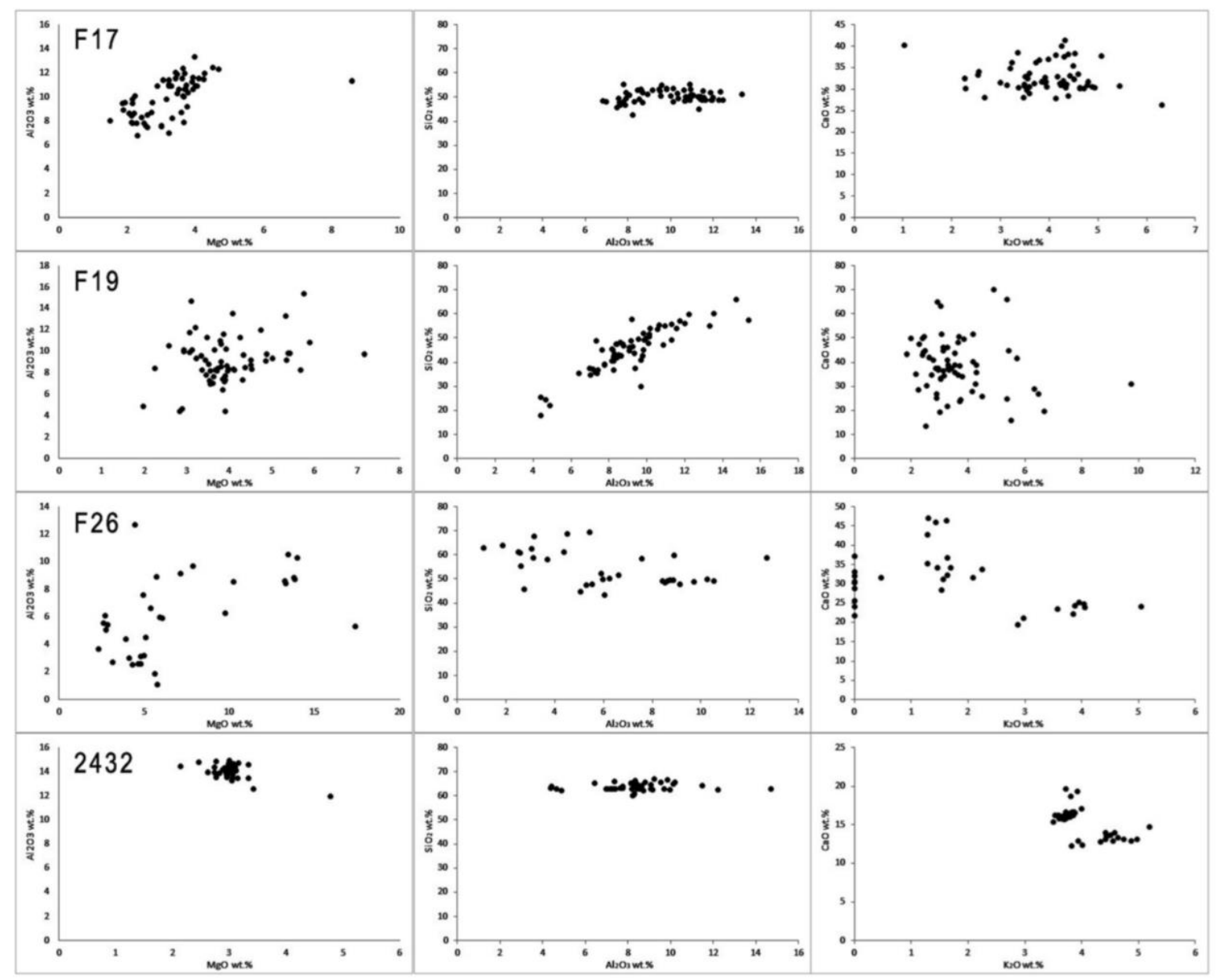

Fig. 8 Bivariate plots of non-reduced compounds (NRC) after renormalisation

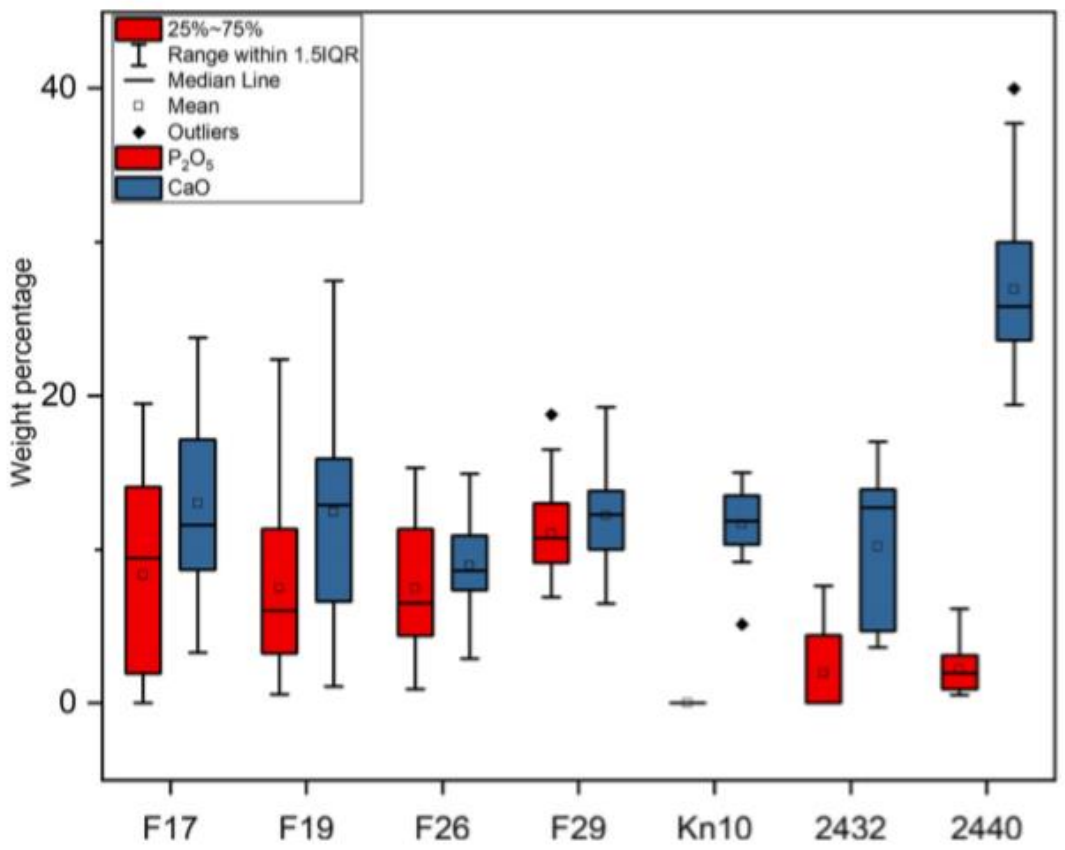

Fig. 9 Box-whisker plot of $\mathrm{CaO}$ and $\mathrm{P}_{2} \mathrm{O}_{5}$ concentrations in slag inclusions 
Samples Kn10 and 2432 were observed to have been folded multiple times during the manufacturing process according to the metallographic microstructure featuring multiple layers with different carbon content (Fig. 5e, f); hence, smithing slag inclusions will most likely occur in these two samples. However, slag inclusions in $\mathrm{Kn} 10$ are highly homogeneous, with an average of $11.6 \mathrm{wt} . \% \mathrm{CaO}$ and thus unlikely to derive from a smithing process. Sample 2432 also shares the same feature, with relatively high $\mathrm{CaO}$ content. Whilst there are some small nodular slag inclusions in the interface between different layers, perhaps introduced during the folding process, their size was too small to carry out EDS analysis reliably (Fig. 11).

Having ruled out other possible sources, it is suggested that most of the slag inclusions with high $\mathrm{CaO}$ content were formed during the Chaogang (fining) process. In this process, when cast iron was re-melted, impurities such as furnace linings, fuel ash and possible additives such as limestone or iron ore (Rostoker and Bronson 1990: 104; Wagner 2008: 36; Zhang and Chen 2018; Lam et al. 2018) will form into slag. With the decarburisation going on, the melting point of the iron rises as the carbon content drops; hence, iron will start to solidify, with some slag trapped inside the metal in the form of slag inclusions. The stirring process, which is supposed to promote the oxidisation, will also create an inhomogeneous redox environment, whereby certain regions might be more oxidising than others; hence, the slag inclusions in these may contain more $\mathrm{FeO}$, which will dilute the concentration of other elements, creating fluctuations of chemical concentration between samples. The high and unevenly distributed $\mathrm{P}_{2} \mathrm{O}_{5}$ found among the slag inclusions is another indicator of this heterogeneous oxidisation process. Similar features recorded in slag inclusions indicate that samples F17, F19 and 2432 were produced in similar processes.

On the other hand, if the process was carried out in a more homogeneous environment, for instance, when the decarburisation was finished in liquid state, or no stirring process was applied, slag inclusions in the final product should have a relatively uniform chemical composition, as seen in samples $\mathrm{F} 29, \mathrm{Kn} 10$ and 2440. The absence of $\mathrm{P}_{2} \mathrm{O}_{5}$ in the slag inclusions in $\mathrm{Kn} 10$ and the relatively low concentration of $\mathrm{P}_{2} \mathrm{O}_{5}$ in 2440 could be due to the fact that the original cast iron used for decarburisation may have contained very little $P$ in the metal.

The data from sample F26 are less conclusive, due to the low quantity of representative slag inclusions available for analysis, but the presence of high $\mathrm{CaO}$ and $\mathrm{P}_{2} \mathrm{O}_{5}$ slag inclusions indicates the sample underwent an oxidisation process but was perhaps more heavily worked and possibly repaired afterwards, with new slag inclusions being introduced.

In the original research work involving the legacy samples reanalysed here (Chen and Han 1999), sample 2432 was interpreted as a combination of Chaogang iron and bloomery 
hammered together, based on the layered metallographic structure and clear distinction between two types of slag inclusions. However, based on the larger dataset of slag inclusion data in this paper, this conclusion was challenged as despite the variable chemical concentration among those two types of slag inclusions, NRC analysis has suggested they have a common technological source, which should be formed during the Chaogang process. Sample 2440 was originally identified as cast iron decarburised through annealing process, and the slag inclusions were considered as cast iron smelting slag, yet the new results suggest these slag inclusions are more likely to be fining slag, as cast-iron smelting slag should either be expected in cast products or contain any $\mathrm{P}_{2} \mathrm{O}_{5}$ based on recent studies on cast iron smelting slag (Zhang 2015; Chen and Zhang 2016; Lam et al. 2018).

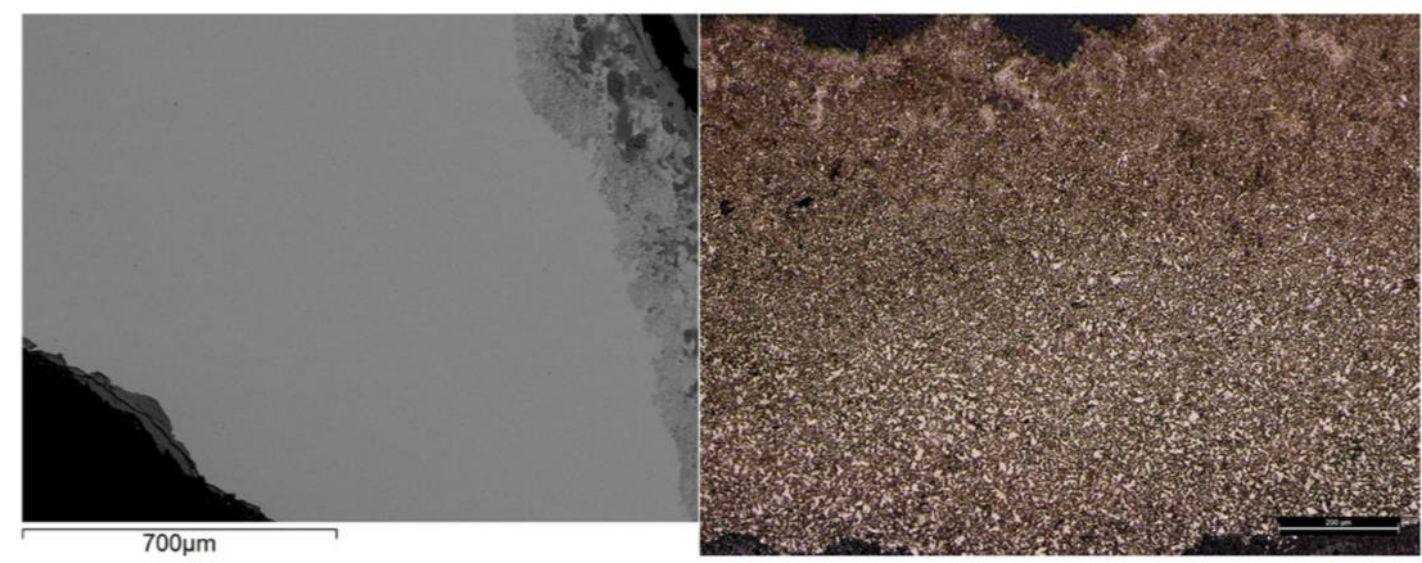

Fig. 10 Back scattered electron image (left) and metallographic structure (right) of sample Kn11, showing a clean matrix without slag inclusions and a microstructure of pearlite and ferrite

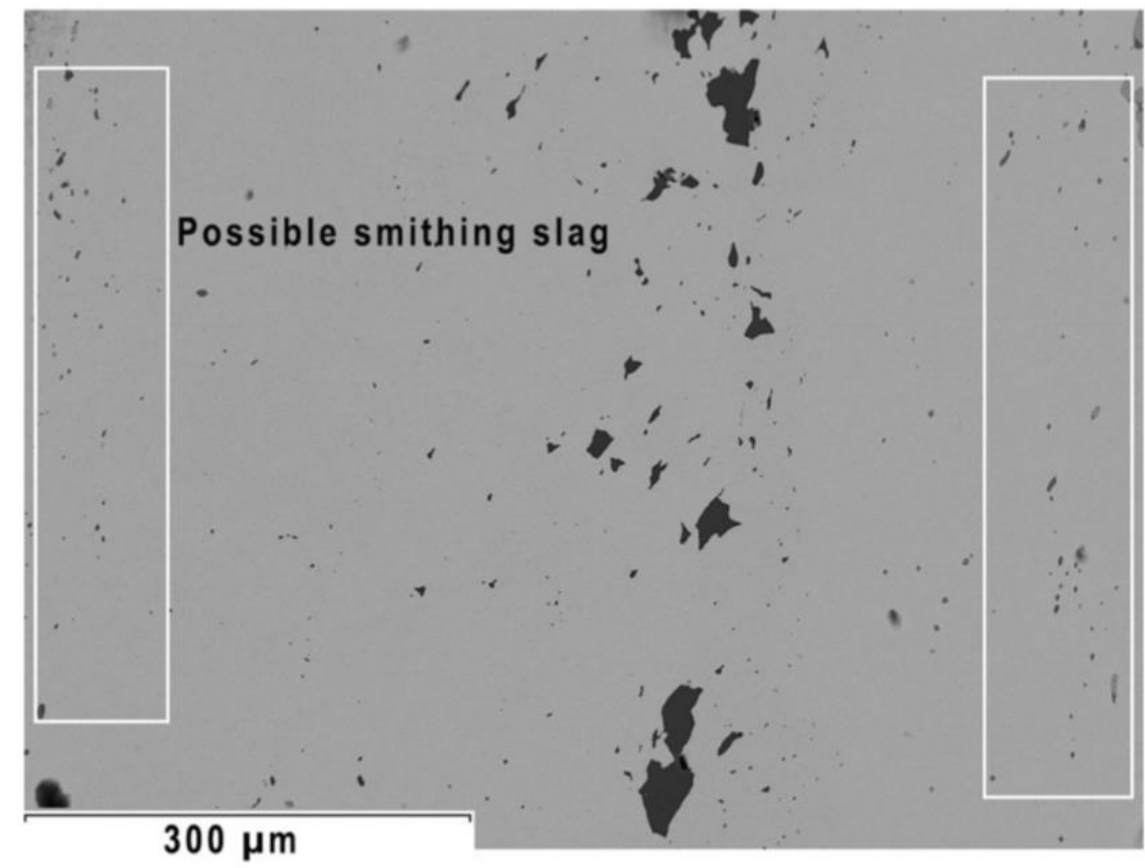

Fig. 11 Possible smithing slag found in sample 2432 


\section{Conclusions}

Building on the current development of analytical approaches to differentiate between direct and indirect iron products, in this paper, we analysed a series of early iron objects recovered from the eastern Guanzhong Plain, using a systematic analytical approach based on metallography and slag inclusion analysis. We obtained a relatively large dataset of slag inclusion compositions per sample and analysed the data with reference to previous research. This procedure, combined with a fundamental understanding of the underlying technological processes and the thermochemical behaviour of different elements, allowed us not only to identify samples as derived from indirect smelting processes, but also to further differentiate their decarburisation techniques.

Based on the results, we can draw the conclusion that during the late Waring States period, various decarburisation techniques were applied for soft iron production based on cast iron smelting in the eastern Guanzhong Plain. In addition to providing the earliest evidence for the application of the Chaogang (fining) technique, this paper provides new pointers for research on the early development of iron production techniques in the Central Plains area. The new evidence suggests that, despite intrinsic differences in technical procedures and costefficiency, solid-state annealing and liquid fining of cast iron co-existed for soft iron production in this region. Whilst iron metallurgy in the Guanzhong Plain has not attracted much research previously, our work suggests that during the late Warring States period, this area was actively engaged in developing and innovating iron production techniques based on cast iron smelting. Future research should further investigate the evolution of these two refining techniques and the circumstances under which each of them would have been employed, in addition to exploring the relationship between the direct and indirect smelting processes in Early Iron Age China.

\section{Acknowledgements}

We are very grateful to the Shaanxi Provincial Institute of Archaeology for all the help and facilities that made this research possible, especially the effort and support from the staff including Zhouyong Sun, Anding Shao, Lianjian Yue and Jianxi Li. We are also indebted to Rubin Han, Yanxiang Li and Xiuhui Li from the Institute of Historical Metallurgy and Materials, USTB, for their kind support and advice. We also want to express our gratitude to colleagues at the UCL Institute of Archaeology, including Michael Charlton, Thilo Rehren, Yijie Zhuang, Tom Gregory, Agnese Benzonelli, Jonathan Wood, Hayley Simon and Ole Nordland. 


\section{Funding information}

This research received funding from the National Social Science Fund of China (18BKG011). Yaxiong Liu's research was funded by a China Scholarship Council (CSC) for his PhD research at the UCL Institute of Archaeology. The paper was facilitated by a research visit from Jianli Chen to Marcos Martinón-Torres, funded through a fellowship by the UCL Institute of Advanced Studies.

\section{References}

Bai C (1994) Analytical report of the sword fragment unearthed from Tomb 2 in Yimen, Baoji. Cultural Relics 9:82-85 (in Chinese)

Bai Y (2004) Study of the iron objected from Per-Qin and Han dynasty, PhD dissertation, Shandong University, Shandong (in Chinese)

Beijing University of Iron and Steel Technology (1975) Preliminary analytical report for the metallographic study of iron objects unearthed in tomb 44 unearthed from the capital of Yan in Yi county, Hebei province. Archaeology 4:241-243 (in Chinese)

Beijing University of Iron and Steel Technology (1976) Analytical report of the iron depot in Mianchi, Henan. Cultural Relics 8:52-58 (in Chinese)

Biggs L, Bellina B, Martinón-Torres M, Pryce TO (2013) Prehistoric iron production technologies in the Upper Thai-Malay Peninsula: metallography and slag inclusion analyses of iron artefacts from Khao Sam Kaeo and Phu Khao Thong. Archaeol Anthropol Sci 5(4):311329

Blakelock E et al (2009) Slag inclusions in iron objects and the quest for provenance: an experiment and a case study. J Archaeol Sci 36(8): 1745-1757

Buchwald VF, Wivel H (1998) Slag analysis as a method for the characterization and provenancing of ancient iron objects. Mater Charact 40(2):73-96

Charlton MF et al (2010) Explaining the evolution of ironmaking recipes - An example from northwest Wales. Journal of Anthropological Archaeology 29(3):352-367

Charlton MF et al (2012) Investigating the production provenance of iron artifacts with multivariate methods. J Archaeol Sci 39(7):2280- 2293

Chen J (1990) Metallurgy of iron and steel (part II steel production). Metallurgical Industry Press, Beijing (in Chinese)

Chen J (2014) New discoveries on the metal working technology in early China. Beijing, Science Press, Beijing (in Chinese) 
Chen J, Han R (1999) Metallographic study ofthe iron objects unearthed from the royal tomb of Chuin Shizishan, Xuzhou. Cultural Relics 7: 84-91 (in Chinese)

Chen J, Han R (2007) Iron and steel technologies in the northern and Central Plains China during Han and Jin dynasty. Peking University Press, Beijing (in Chinese)

Chen J, Zhang Z (2016) Methods to differentiate finning technique based on slag analysis. Cultural Relics in Southern China 1:115-121 (in Chinese)

Chen $\mathrm{J}$ et al (2009) Manufacturing technique of the Bronze-Iron object from tomb 27 in Liangdai village site. China Science 39(9):1574- 1581 (in Chinese)

Chen $J$ et al (2012) Iron objects unearthed from Siwa culture tomb in Gansu and the origin of the iron metallurgy in China. Cultural Relics 8:45-53 (in Chinese)

Craddock PT (1995) Early metal mining and production. Edinburgh University Press, Edinburgh

Dillmann P, L'Héritier M (2007) Slag inclusion analyses for studying ferrous alloys employed in French medieval buildings: supply of materials and diffusion of smelting processes. $J$ Archaeol Sci 34(11):1810-1823

Disser A et al (2014) Iron reinforcements in Beauvais and Metz Cathedrals: from bloomery or finery? The use of logistic regression for differentiating smelting processes. J Archaeol Sci 42:315-333

Goldstein JI, Huss GR, Scott ERD (2017) Ion microprobe analyses of carbon in Fe -Ni metal in iron meteorites and mesosiderites. Geochim Cosmochim Acta 200:367-407

Gordon RB (1997) Process deduced from ironmaking wastes and artefacts. J Archaeol Sci 24(1):9-18

Guo M et al (2014) Scientific study of the iron objects unearthed from a Warring State cemetery in Zhaitouhe, Huangling, Shaanxi Province. Archaeology And Cultural Relics 2:114-120 (in Chinese)

Han R (1989) Examination of iron objects unearthed fromTianma-Qucun site. Tianma-Qucun. Science Press. III, Beijing, pp 1178-1180 (in Chinese)

Han R (1998) Metallographic study of the iron objects in China dated before 5th century BC. Cultural Relics 2:87-96 (in Chinese)

Han R, Ko T (2007) History of science and technology in China: mining and metallurgy. Science Press, Beijing (in Chinese) 
Han R, et al. (1999) "Identification and study of the bronze objects with iron blade unearthed from the Guo Cemetery." from: Henan Institute of Cultural Relics, Excavation team in Sanmenxia. "Guo Cemetery in Sanmenxia". Beijing: Cultural Relics Press (in Chinese)

Hua J (1982) Discussion on high strength cast iron from Han and Wei dynasties. Studies In The History of Natural Sciences 1(1):1-20 (in Chinese)

Hua J (1999) Metal technology in ancient China. Elephant press, Beijing (in Chinese) Hua $J$ et al (1960) Preliminary metallography analytical results of iron objects dated to Warring States period and Han dynasty. Acta Archaeologica Sinica (1):73-88 (in Chinese)

Huang Q (2013) Investigation and slag analysis on iron smelting sites in Guigang district, Guangxi, Lijiang, Lijiang Publishing house (in Chinese)

Huang $Q$ et al (2016) Study of early iron metallurgy based on slag analysis. Journal of National Museum of China 11:145-153 (in Chinese)

lles L, Martinón-Torres M (2009) Pastoralist iron production on the Laikipia Plateau, Kenya: wider implications for archaeometallurgical studies. J Archaeol Sci 36(10):2314-2326

Killick, D. and R. B. Gordon (1988). The mechanism of iron production in the bloomery furnace. Proceedings of the 26th International Archaeometry Symposium: held at University of Toronto, Toronto, Canada, May 16th to May 20th, 1988, University of Toronto. Archaeometry Laboratory

King $P$ (2005) The production and consumption of bar iron in early modern England and Wales. Econ Hist Rev 58(1):1-33

Ko T et al (1993) Preliminary study of early iron objects unearthed in Henan province. Cultural Relics in Central Plain 1:99-107 (in Chinese)

Lam W et al (2018) An iron production and exchange system at the center of the Western Han Empire: scientific study of iron products and manufacturing remains from the Taicheng site complex. J Archaeol Sci 100:88-101

Larreina-Garcia D, et al. (2018) "Bloomery iron smelting in the Daye County (Hubei): technological traditions in Qing China." Archaeological Research in Asia 16:148-165

Li Y et al (2019) Early iron objects of southwest China: a case study of iron objects excavated from Qiaogoutou cemetery site, Sichuan Province. Archaeological and Anthropological Sciences 11(4): 1187-1198

Li Z (1975) Discussion on the iron and steel working technique in early feudalism China. Acta Archaeologica Sinica 2:1-22 (in Chinese) 
Li Z (1982) Metallographicstudyofthe Haniron objects unearthed from Zhenping, Henan province. Archaeology 3:320-321 (in Chinese)

Miao C et al (1993) Technological development of iron production in Henan based on the examination of iron objects. Cultural Relics in Central Plains 4:91-100 (in Chinese)

McDonnell JG (1991) A model for the formation of smithing slags. Materialy Archeologiczne 26:23-26

Nanjing Museum (1974) Tomb No.2 dated to Spring and Autumn period in Liuhe, Jiangsu province. Archaeology 2:116-120 (in Chinese)

Pleiner R (2000) Iron in archaeology: the European bloomery smelters. Archeologický ústav AVČR, Prague

Pleiner R (2006) Iron in archaeology: early European blacksmiths. Archeologický ústav AV Čr, Prague

Rehren T, et al (2007) Decisions set in slag: the human factor in African iron smelting. In: La Niece S, Hook DR, Craddock PT(eds), Metals and mines: studies in archaeometallurgy. Archetype, British Museum, London, pp 211-218

Rostoker W, Bronson B (1990). Pre-industrial iron: its technology and ethnology. Archeomaterials Monograph No. 1, Philadelphia

Serneels V, Perret S (2003) Quantification of smithing activities based on the investigation of slag and other material remains. Archaeometallurgy in Europe 1:469-478

Shandong Museum (1977) Eastern Zhou tomb with human sacrifice in Linzi, Langjiazhuang. Acta Archaeologica Sinica 1:73-104 (in Chinese)

Sun W (2009) Study of the Xinfeng Qin cemetery. MA dissertation. Northwest University, Xi'an (in Chinese)

Wagner DB (1985) Dabieshan: traditional Chinese iron-production techniques practised in southern Henan in the twentieth century. Curzon Press, London

Wagner DB (1989) Toward the reconstruction of ancient Chinese techniques for the production of malleable cast iron. East Asian Institute occasional papers 4:3-72

Wagner DB (2008) Science and civilisation in China: science and civilisation in China: Vol. 5, Chemistry and Chemical Technology. Ferrous Metallurgy/by Donald B. Wagner, Cambridge University Press

Yang K (1960) A brief history of the development of traditional iron and steel productiontechniques in China. Shanghai Peoples' Publishing House, Shanghai (in Chinese) 
Yang K (1980) The innovation of iron implements and its impact in history of China. Historical Research 5:89-98 (in Chinese)

Yang K (1982) The development history of iron smelting technology in ancient China. Shanghai People's Publishing House, Shanghai (in Chinese)

Yang $\mathrm{J}$ et al (2014) Scientific analysis of iron objects unearthed from a military camp in Paomaquan Great wall in Changping, Beijing - discussion about the identification method for finning technique. The Chinese Journal for The History of Science and Technology 35(2):177187 (in Chinese)

Ye J (1975) Initial investigation of iron and bronze tools unearthed from the miningsitein Tonglushan.Cultural Relics 2:19-25 (in Chinese)

Zhang Z (2015) Archaeometalurgical study of iron foudry site in Dongpingling, Shandong. MSc dissertation, Peiking University, Beijing (in Chinese)

Zhang Z, Chen J (2018) A preliminary discussion on Phosphorus in cast iron smelting. Cultural Relics in Southern China 3:196-211 (in Chinese)

Zhao Q et al (1985) Re-discussion about the iron foundry site in Tieshenggou, Gong county. Acta Archaeologica Sinica 2:157-183 (in Chinese)

Publisher's note Springer Nature remains neutral with regard to jurisdictional claims in published maps and institutional affiliations. 